\title{
Electrostatic Control of Au Nanorod Formation in Automated Micro- Segmented Flow Synthesis
}

\author{
Andrea Knauer*, Danja Kuhfuss, J. Michael Köhler*
}

Technische Universität Ilmenau, Institute of Micro- und Nanotechnologies, Institute of Chemistry and Biotechnology, Department of Physical Chemistry and Microreaction Technology, D-98684 Ilmenau, Germany

*Corresponding Author: Dr. Andrea Knauer, Technische Universität Ilmenau, Institute of Micro- and Nanotechnologies, Institute of Chemistry and Biotechnology, Department of Physical Chemistry and Microreaction Technology PF 1005 65, D-98684 IImenau, Germany, andrea.knauer@tu-ilmenau.de

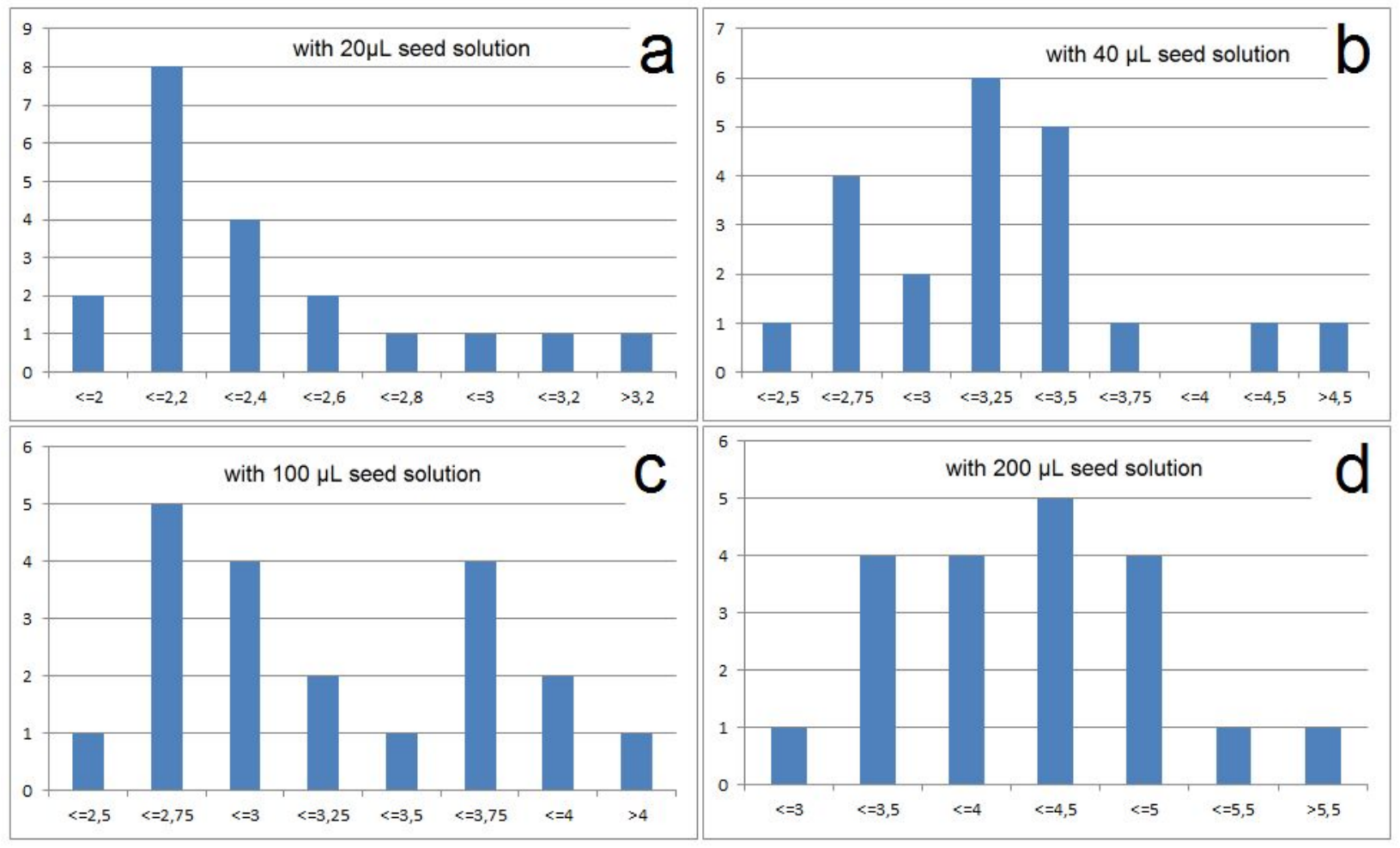

Fig. S1: The histograms of aspect ratios for the four presented seed particle volume ratios clearly hint for an increasing aspect ratio in case of higher volumes of seed particle solution. 